\title{
Glycemic Load, Glycemic Index, and Carbohydrate Intake in Relation to Risk of Cholecystectomy in Women
}

\section{Citation}

Tsai, Chung-Jyi, Michael F. Leitzmann, Walter C. Willett, and Edward L. Giovannucci. 2005. "Glycemic Load, Glycemic Index, and Carbohydrate Intake in Relation to Risk of Cholecystectomy in Women." Gastroenterology 129 (1): 105-12. https://doi.org/10.1053/j.gastro.2005.05.016.

\section{Permanent link}

http://nrs.harvard.edu/urn-3:HUL.InstRepos:41392081

\section{Terms of Use}

This article was downloaded from Harvard University's DASH repository, and is made available under the terms and conditions applicable to Other Posted Material, as set forth at http:// nrs.harvard.edu/urn-3:HUL.InstRepos:dash.current.terms-of-use\#LAA

\section{Share Your Story}

The Harvard community has made this article openly available. Please share how this access benefits you. Submit a story.

Accessibility 


\title{
CLINICAL-LIVER, PANCREAS, AND BILIARY TRACT
}

\section{Glycemic Load, Glycemic Index, and Carbohydrate Intake in Relation to Risk of Cholecystectomy in Women}

\author{
CHUNG-JYI TSAI,*,* MICHAEL F. LEITZMANN, ${ }^{*}{ }^{\S}$ WALTER C. WILLETT, $*, \boldsymbol{\uparrow}$ \\ and EDWARD L. GIOVANNUCCI*, \\ *Channing Laboratory, Department of Medicine, Harvard Medical School and Brigham and Women's Hospital, Boston, Massachusetts; \\ ${ }^{\dagger}$ Division of Digestive Diseases and Nutrition, University of Kentucky Medical Center, Lexington, Kentucky; ${ }^{\circledR}$ Division of Cancer Epidemiology \\ and Genetics, National Cancer Institute, Bethesda, Maryland; and "Departments of Nutrition and Epidemiology, Harvard School of Public \\ Health, Boston, Massachusetts
}

\section{See editorial on page 373 .}

Background \& Aims: High-carbohydrate diets with a high glycemic response may exacerbate the metabolic consequences of the insulin-resistance syndrome. The effect on the incidence of gallstone disease is not clear. Methods: We examined the associations between high-carbohydrate diets with a high glycemic response and the risk of cholecystectomy in a cohort of women who were aged from 35 to 61 years in 1984 and had no history of gallstone disease. As part of the Nurses' Health Study, the women reported on questionnaires mailed to them every 2 years both their carbohydrate intake and whether they had undergone cholecystectomy. Results: During 16 years of follow-up, we ascertained 5771 new cases of cholecystectomy. After adjusting for age and other known or suspected risk factors in a multivariate model, the relative risk for the highest compared with the lowest quintile of dietary carbohydrate was 1.35 (95\% Cl: 1.17-1.55, $P$ for trend < .0001). The relative risks for the highest compared with the lowest quintile were 1.50 for glycemic load (95\% Cl: 1.32-1.71, $P$ for trend < .0001) and 1.32 for glycemic index (95\% Cl: 1.20-1.45, $P$ for trend < .0001). Independent positive associations were also seen for intakes of starch and sucrose. Conclusions: Our findings suggest that a higher intake of carbohydrate, dietary glycemic load, and glycemic index may enhance risk of cholecystectomy in women.

G allstone disease is a common condition affecting J approximately $10 \%-25 \%$ of the adult population in the United States and other developed countries ${ }^{1,2}$ and has increasingly become a leading cause of abdominal morbidity leading to hospital admissions. ${ }^{3,4}$ Consequently, preventive measures to decrease the occurrence of gallstone disease are required.
Among people in most Western countries, including the United States, an estimated $80 \%$ of gallstones are cholesterol stones. ${ }^{5}$ Cholesterol gallstones have many causative factors, but biliary hypersecretion of cholesterol is an important determinant. ${ }^{6}$ Low plasma high-density lipoprotein (HDL) cholesterol and high plasma triglyceride levels are associated with a greater risk for gallstones. ${ }^{7}$ High intake of carbohydrates produces these same lipid changes ${ }^{8,9}$ and, thus, may increase the risk for gallstones. In addition, recent findings indicate that hyperinsulinemia may enhance gallstone development. ${ }^{10,11}$ Carbohydrates with different physical forms, chemical structures, and particle sizes may induce distinct plasma glucose and insulin responses. The physiologic response to carbohydrates can be quantified by the glycemic index. ${ }^{12}$ Substituting foods with low glycemic indices for those with high indices reduces serum insulin and glucose response. ${ }^{13}$ A chronic high dietary glycemic load, which increases insulin demand, may exacerbate insulin resistance $^{14}$ and, hence, may further increase risk for gallstones.

Although insulin resistance, chronic hyperglycemia, and associated disorders of lipid metabolism are important determinants of gallstone development, the significance of dietary glycemic load and glycemic index in predicting risk of gallstone disease has rarely been examined in humans. Thus, in a large cohort of US women, we examined prospectively whether diets characterized by high glycemic load and glycemic index could promote the occurrence of gallstone disease.

\footnotetext{
Abbreviation used in this paper: SFFQ, semiquantitative food-frequency questionnaire.

(C) 2005 by the American Gastroenterological Association 0016-5085/05/\$30.00 doi:10.1053/j.gastro.2005.05.016
} 


\section{Materials and Methods}

\section{Study Population}

The Nurses' Health Study was initiated in 1976 when 121,700 female registered nurses, predominantly white, aged 30 to 55 years completed a mailed questionnaire on their medical history and lifestyle characteristics. Every 2 years, follow-up questionnaires were sent to update information on exposures and to identify newly diagnosed illnesses. In 1984, we collected detailed information on the carbohydrate-containing foods with an expanded 126-item, semiquantitative foodfrequency questionnaire (SFFQ). After repeated mailings, 81,757 women returned the SFFQ and satisfied a priori criteria of daily energy intakes between $600 \mathrm{kcal}$ and $3500 \mathrm{kcal}$. We further excluded women with a prior diagnosis of gallstone disease, diabetes, or cancer. The final baseline population was 70,408 women aged 35 to 61 years in 1984. On average, more than $90 \%$ of participants responded to each subsequent biennial questionnaire, and approximately $80 \%$ completed each repeated dietary questionnaire during the follow-up period. ${ }^{15}$ This study was approved by the institutional review board on the use of human subjects in research of the Brigham and Women's Hospital in Boston.

\section{Assessment of Diet}

Because this analysis focused on carbohydrate-containing foods, we based dietary information on the expanded 1984 SFFQ $^{16}$ and on repeated assessments in 1986, 1990, 1994, and 1998. Participants were asked to indicate the frequency, on average, of consuming a typical serving of selected foods during the previous year. There were 9 possible response options, ranging from never or less than once per month to 6 or more times per day. Nutrient scores were computed by multiplying the frequency of consumption of each unit of food from the SFFQ by the nutrient content of the specified portion according to food-composition tables from the US Department of Agriculture. ${ }^{17}$

For each participant, we derived an average dietary glycemic index value, which ranks foods on the basis of the incremental glucose response and insulin demand for a given amount of carbohydrate. ${ }^{18}$ We calculated the average dietary glycemic index for each woman by summing the products of the carbohydrate content per serving for each food multiplied by the reported average number of servings of that food per day, times its glycemic index, and then divided this sum by the total amount of daily carbohydrate intake. For these calculations, we used data for the carbohydrate content in each serving reported by the US Department of Agriculture. ${ }^{17} \mathrm{We}$ also calculated glycemic load by multiplying the carbohydrate content of each food by its glycemic index, then multiplied this value by the frequency of consumption, and summed the values from all foods. ${ }^{19}$ Dietary glycemic load represents the quality and quantity of carbohydrates and the interaction between the two. Each unit of dietary glycemic load represents the equivalent glucose response of 1 gram of carbohydrate from pure glucose. A full description of the SFFQ and the procedures used for calculating nutrient intake, as well as data on reproducibility and validity, were reported previously. ${ }^{16}$ The correlation coefficient for energy-adjusted carbohydrate intake between the SFFQs and diet records was $0.73 .{ }^{19}$ All nutrients, as well as the glycemic index and glycemic load, were adjusted for total energy intake using regression analysis. This approach is based on the concept that the composition of the diet, independent of total energy intake, is more relevant to dietary recommendations. ${ }^{16}$

\section{Identification of Cases of Cholecystectomy}

We inquired about occurrence and date of cholecystectomy on each biennial questionnaire starting in 1980. A validation study of the self-report was conducted in a random sample of 50 nurses who reported a cholecystectomy in 1982. Forty-three out of 50 participants responded, and, of these, all reiterated their earlier report, and surgery was confirmed in all 36 for whom medical records could be obtained. We chose cholecystectomy as the primary end point, mainly because women are more likely to report accurately the occurrence and timing of a surgical procedure rather than untreated gallstones. In addition, symptomatic gallstones are the main indication for cholecystectomy. ${ }^{20}$ In contrast, only a minor proportion of asymptomatic gallstones are diagnosed, typically incidentally, making this clinically less relevant condition an unreliable end point.

\section{Statistical Analysis}

We calculated person-time of follow-up for each participant from the date of return of the 1984 questionnaire to the date of cholecystectomy, cancer, date of last questionnaire return, death, or the end of the study period in 2000, whichever came first. Women were categorized in quintiles of carbohydrate intake, dietary glycemic load, and overall dietary glycemic index. Incidence rates were calculated by dividing the number of events by person-years of follow-up in each quintile. Relative risks were calculated as the incidence rate of cholecystectomy among women in different categories of exposure compared with the incidence rate among women in the reference category, with adjustment for age in 5-year categories. The incidence of cholecystectomy was examined in relation to the cumulative average of exposure variables from all available questionnaires up to the start of each 2-year follow-up interval, using methods for repeated measurement. ${ }^{21}$ Age-adjusted relative risks were calculated using the MantelHaenszel summary estimator. ${ }^{22}$ Multivariate relative risks were computed using the Cox proportional hazards regression model. ${ }^{23}$ In multivariate analyses, we simultaneously adjusted for the known or suspected confounding variables: time period, age, body mass index, weight change in the previous 2-year interval, physical activity, parity, oral contraceptive use, postmenopausal hormone use, pack-years of smoking, thiazide diuretics, nonsteroidal anti-inflammatory drugs, intake of total energy, energy-adjusted dietary fiber, alcohol, and coffee. Tests of trend across increasing quintiles of carbohydrate intake, dietary glycemic load, and overall dietary glycemic index were 
Table 1. Baseline Characteristics of 70,408 US Women According to Quintiles of Energy-Adjusted Intake of Carbohydrate: the Nurses' Health Study

\begin{tabular}{|c|c|c|c|c|c|c|}
\hline \multirow[b]{2}{*}{ Characteristics } & \multicolumn{6}{|c|}{ Quintiles of carbohydrate intake } \\
\hline & $\begin{array}{c}1 \text { (lowest) } \\
(n=14,078)\end{array}$ & $\begin{array}{c}2 \\
(n=13,350)\end{array}$ & $\begin{array}{c}3 \\
(n=14,407)\end{array}$ & $\begin{array}{c}4 \\
(n=13,796)\end{array}$ & $\begin{array}{c}5 \text { (highest) } \\
(n=14,147)\end{array}$ & $\begin{array}{l}P \text { value } \\
\text { for trend }\end{array}$ \\
\hline Mean intake (g/day) & 141 & 170 & 185 & 200 & 228 & $<.0001$ \\
\hline Age $(y)^{a}$ & 47.7 & 47.5 & 47.6 & 48.1 & 49.0 & $<.0001$ \\
\hline Current smoker (\%) & 31 & 23 & 20 & 19 & 18 & $<.0001$ \\
\hline Current body mass index $\left(\mathrm{kg} / \mathrm{m}^{2}\right)^{a}$ & 25.1 & 25.0 & 24.9 & 24.6 & 24.2 & $<.0001$ \\
\hline Physical activity (METs) ${ }^{a b}$ & 7.4 & 7.5 & 7.5 & 7.6 & 7.9 & $<.0001$ \\
\hline Any weight loss in prior $2 \mathrm{yr}(\%)$ & 26.7 & 26.5 & 26.6 & 27.0 & 27.7 & .04 \\
\hline Total energy (kcal/day) & 1698 & 1780 & 1797 & 1766 & 1691 & .07 \\
\hline History of oral contraceptive use (\%) & 52 & 50 & 49 & 49 & 46 & $<.0001$ \\
\hline Current use of HRT $(\%)^{c}$ & 21.8 & 21.6 & 21.3 & 21.7 & 21.8 & .3 \\
\hline Regular use of aspirin (\%) & 28 & 27 & 27 & 28 & 32 & $<.0001$ \\
\hline Regular use of thiazide diuretics (\%) & 13.8 & 11.1 & 11.3 & 11.1 & 11.3 & $<.0001$ \\
\hline Protein $(g / \text { day })^{a}$ & 78 & 75 & 72 & 69 & 63 & $<.0001$ \\
\hline Alcohol $(g / d a y)^{a}$ & 14.9 & 7.9 & 5.6 & 4.2 & 2.7 & $<.0001$ \\
\hline Coffee $(\text { cups })^{a}$ & 2.2 & 2.0 & 1.8 & 1.7 & 1.4 & $<.0001$ \\
\hline Saturated fat $(g / \text { day })^{a}$ & 25.5 & 23.8 & 22.4 & 20.9 & 18.0 & $<.0001$ \\
\hline Polyunsaturated fat $(g / d a y)^{a}$ & 13.0 & 12.4 & 11.9 & 11.4 & 10.1 & $<.0001$ \\
\hline Monounsaturated fat $(g / d a y)^{c}$ & 26.1 & 24.2 & 22.8 & 21.1 & 18.0 & $<.0001$ \\
\hline Trans fat (g/day) & 3.6 & 3.6 & 3.5 & 3.3 & 2.8 & $<.0001$ \\
\hline Dietary fiber (g/day) & 13.4 & 15.3 & 16.4 & 17.4 & 19.4 & $<.0001$ \\
\hline
\end{tabular}

aValues expressed as means.

${ }^{b}$ Metabolic equivalent tasks per week, defined as a multiple of metabolic equivalent of sitting at rest. cHRT, hormone replacement therapy. Only postmenopausal women were included.

conducted by assigning the median value to each quintile and treating these as a single continuous variable. All relative risks are presented with $95 \%$ confidence intervals (CI), and all reported $P$ values are 2-sided. All analyses were performed with Statistical Analysis System software, release 8.2 (SAS Institute, Cary, North Carolina).

\section{Results}

At baseline in 1984, there was an approximately 1.5-fold difference in the mean energy-adjusted carbohydrate intake between the highest and lowest quintiles in this cohort (Table 1). Women with higher carbohydrate intake tended to consume less protein and saturated, trans, monounsaturated, and polyunsaturated fats. Women who reported higher intake of carbohydrate tended to be leaner, more physically active, nonsmokers, and to consume less alcohol and coffee but more dietary fiber.

During 932,676 person-years of follow-up from 1984 to 2000, we ascertained 5771 cases of cholecystectomy. After adjustment for age, the estimated relative risk for women in the highest quintile compared with those in the lowest quintile of energy-adjusted dietary glycemic load was 1.13 (95\% CI: $1.03-1.23, P$ for trend $=.0009$ ) (Table 2, model 1). This association was slightly strengthened after further adjustment for other known risk factors for gallstone. In an analysis that included age, body mass index, recent weight change, parity, oral contraceptive use, hormone replacement therapy, physical activity, pack-years of smoking, thiazide diuretics, nonsteroidal anti-inflammatory drugs, total energy intake, dietary fiber, protein, alcohol, and coffee (Table 2, model 2), the relative risk for the highest compared with the lowest quintile of dietary glycemic load was 1.32 (95\% CI: $1.18-1.47, P$ for trend $=.0001)$. With additional adjustment with saturated and trans fats (Table 2, model 3), the relative risk was 1.50 (95\% CI: 1.32-1.71, $P$ for trend $<.0001$ ) when extreme quintiles were compared.

We further adjusted for intakes of all types of fat (Table 2, model 4). In this model, in which all fats, protein, and total energy intake were held constant, glycemic load represents the effect of substituting highglycemic-index carbohydrates for low-glycemic-index carbohydrates on the risk of cholecystectomy. Compared with carbohydrates with a low glycemic index, carbohydrates with a high glycemic index were associated with increased risk of cholecystectomy. The relative risk for the highest compared with the lowest quintile of glycemic load was 1.40 (95\% CI: $1.22-1.62, P$ for trend $<.0001)$. Similar findings for glycemic load were observed when all types of fats were replaced with carbohydrate in the multivariate model, with a multivariate 
Table 2. Adjusted Relative Risks of Cholecystectomy According to Quintiles of Energy-Adjusted Intakes of Glycemic Load, Glycemic Index, and Carbohydrate Intake Among US Women in the Nurses' Health Study, 1984-2000

\begin{tabular}{|c|c|c|c|c|c|c|}
\hline & \multicolumn{6}{|c|}{ Quintiles } \\
\hline & 1 (lowest) & 2 & 3 & 4 & 5 (highest) & $\begin{array}{l}P \text { value } \\
\text { for trend }\end{array}$ \\
\hline \multicolumn{7}{|l|}{ Glycemic load ${ }^{a}$} \\
\hline Cases & 981 & 1122 & 1196 & 1308 & 1164 & - \\
\hline Person-years & 184,830 & 185,938 & 186,733 & 187,103 & 188,072 & - \\
\hline $\begin{array}{l}\text { Model 1: Age- } \\
\text { adjusted }(95 \% \mathrm{Cl})\end{array}$ & 1.00 & $1.12(1.03-1.22)$ & $1.18(1.08-1.28)$ & $1.28(1.18-1.39)$ & $1.13(1.03-1.23)$ & .0009 \\
\hline $\begin{array}{l}\text { Model 2: Multivariate } \\
\quad(95 \% \mathrm{Cl})\end{array}$ & 1.00 & $1.10(1.00-1.21)$ & $1.20(1.09-1.31)$ & $1.35(1.23-1.49)$ & $1.32(1.18-1.47)$ & .0001 \\
\hline $\begin{array}{l}\text { Model 3: Multivariate } \\
\quad(95 \% \mathrm{Cl})\end{array}$ & 1.00 & $1.14(1.04-1.25)$ & $1.27(1.15-1.40)$ & $1.48(1.33-1.64)$ & $1.50(1.32-1.71)$ & $<.0001$ \\
\hline $\begin{array}{l}\text { Model 4: Multivariate } \\
\quad(95 \% \mathrm{Cl})\end{array}$ & 1.00 & $1.12(1.02-1.23)$ & $1.23(1.11-1.37)$ & $1.41(1.25-1.59)$ & $1.40(1.22-1.62)$ & $<.0001$ \\
\hline \multicolumn{7}{|l|}{ Glycemic index ${ }^{b}$} \\
\hline Cases & 970 & 1141 & 1276 & 1222 & 1162 & - \\
\hline Person-years & 186,332 & 186,334 & 187,336 & 187,165 & 185,508 & - \\
\hline $\begin{array}{l}\text { Model 1: Age- } \\
\text { adjusted }(95 \% \mathrm{Cl})\end{array}$ & 1.00 & $1.18(1.08-1.28)$ & $1.32(1.22-1.44)$ & $1.28(1.18-1.40)$ & $1.27(1.17-1.39)$ & $<.0001$ \\
\hline $\begin{array}{l}\text { Model 2: Multivariate } \\
\quad(95 \% \mathrm{Cl})\end{array}$ & 1.00 & $1.14(1.05-1.25)$ & $1.32(1.21-1.44)$ & $1.31(1.19-1.43)$ & $1.33(1.21-1.46)$ & $<.0001$ \\
\hline $\begin{array}{l}\text { Model 3: Multivariate } \\
\qquad(95 \% \mathrm{Cl})\end{array}$ & 1.00 & $1.14(1.04-1.24)$ & $1.31(1.20-1.42)$ & $1.30(1.18-1.42)$ & 1.32 (1.20-1.45) & $<.0001$ \\
\hline $\begin{array}{l}\text { Model 4: Multivariate } \\
\quad(95 \% \mathrm{Cl})\end{array}$ & 1.00 & $1.13(1.04-1.23)$ & $1.30(1.19-1.42)$ & $1.29(1.17-1.41)$ & $1.31(1.18-1.44)$ & $<.0001$ \\
\hline \multicolumn{7}{|l|}{ Carbohydrate intake ${ }^{c}$} \\
\hline Cases & 1007 & 1047 & 1241 & 1354 & 1122 & - \\
\hline Person-years & 183,217 & 183,761 & 185,963 & 191,168 & 188,566 & - \\
\hline $\begin{array}{l}\text { Model 1: Age- } \\
\text { adjusted }(95 \% \mathrm{Cl})^{a}\end{array}$ & 1.00 & $1.02(0.94-1.12)$ & $1.18(1.08-1.28)$ & $1.23(1.13-1.33)$ & $1.02(0.93-1.11)$ & .08 \\
\hline $\begin{array}{l}\text { Model 2: Multivariate } \\
\qquad(95 \% \mathrm{Cl})^{b}\end{array}$ & 1.00 & $1.00(0.91-1.10)$ & $1.17(1.07-1.29)$ & $1.27(1.16-1.41)$ & $1.16(1.04-1.30)$ & .0001 \\
\hline $\begin{array}{l}\text { Model 3: Multivariate } \\
\quad(95 \% \mathrm{Cl})^{b}\end{array}$ & 1.00 & $1.04(0.95-1.15)$ & $1.26(1.14-1.40)$ & $1.42(1.27-1.59)$ & $1.35(1.17-1.55)$ & $<.0001$ \\
\hline $\begin{array}{l}\text { Model 4: Multivariate } \\
\qquad(95 \% \mathrm{Cl})^{b}\end{array}$ & 1.00 & $1.02(0.92-1.12)$ & $1.20(1.08-1.35)$ & $1.32(1.16-1.51)$ & $1.21(1.03-1.43)$ & .003 \\
\hline
\end{tabular}

NOTE. Model 1: RR, relative risk adjusting for age (5-year categories); 95\% Cl: 95\% confidence interval.

Model 2: RR, relative risk adjusting for age (1-year categories), time periods (1980-1982, 1982-1984, 1984-1986, 1986-1988, 1988-1990, 1990-1992, 1992-1994, 1994-1996, 1996-1998, 1998-2000); body mass index at the beginning of each 2-year follow-up interval (<20.00, $20.00-22.49,22.50-24.99,25.00-27.49,27.50-29.99,30.00-32.49,32.50-34.99,35.00-37.49$, 37.50-39.99, and $\geq 40$ ); respectively, weight change in the previous 2 years ( $\geq 10$ pound weight loss, 5.0-9.9 pound weight loss, maintained weight \pm 4.9 pounds, $5.0-$ 9.9 pound weight gain, $\geq 10$ pound weight gain); parity $(0,1,2-3, \geq 4$ births); oral contraceptive use (ever, never), hormone replacement therapy (premenopausal, postmenopausal without hormone replacement therapy, postmenopausal with past hormone replacement therapy, and postmenopausal with current hormone replacement therapy); physical activity (quintiles); pack-years of smoking $(0,1-9,10-24,25-44,45-64$, $\geq 65$ ); thiazide diuretics (yes or no); nonsteroidal anti-inflammatory drugs (0,1-6, $\geq 7$ times per week, and dose unknown); intake of total energy (quintiles); energy-adjusted dietary fiber (quintiles); energy-adjusted protein (quintiles); alcohol (0, 0.1-4.9, 5.0-14.9, 15.0-29.9, $\geq 30.0$ grams per day); and coffee $(0,1,2-3,4+$ cups per day).

Model 3: model 2 with additional adjustment for saturated and trans fats (quintiles).

Model 4: model 2 with additional adjustment for saturated fat, trans fat, monounsaturated fat, and polyunsaturated fat (quintiles).

auintile cut-points of glycemic load: <8350, 8350-9443, 9444-10,340, 10,341-11,438, >11,438.

${ }^{b}$ Quintile cut-points of glycemic index: $<50.5,50.5-52.6,52.7-54.3,54.4-56.2,>56.2$.

'Quintile cut-points of carbohydrate: $<161,161-177,178-192,193-209,>209$.

adjusted relative risk of 1.47 (95\% CI: $1.22-1.77, P$ for trend $<.0001$ ) when extreme quintiles of glycemic load were compared.

The quality of carbohydrate as classified by its glycemic index was significantly associated with the risk of cholecystectomy. After adjustment for age, the estimated relative risk for women in the highest quintile compared with those in the lowest quintile of energy-adjusted dietary glycemic index was 1.27 (95\% CI: 1.17-1.39, $P$ for trend $<.0001$ ) (Table 2 , model 1 ). In a multivariate analysis that included the same covariates as those for glycemic load (Table 2, model 2), the relative risk for the 
Table 3. Adjusted Relative Risks of Cholecystectomy According to Quintiles of Intakes of Types of Carbohydrate Among US Women in the Nurses' Health Study, 1984-2000

\begin{tabular}{|c|c|c|c|c|c|c|}
\hline & \multicolumn{6}{|c|}{ Quintiles } \\
\hline & 1 (lowest) & 2 & 3 & 4 & 5 (highest) & $\begin{array}{l}P \text { value } \\
\text { for trend }\end{array}$ \\
\hline \multicolumn{7}{|l|}{ Starch } \\
\hline $\begin{array}{l}\text { Model 1: Age-adjusted } \\
\quad(95 \% \mathrm{Cl})\end{array}$ & 1.00 & $1.17(1.07-1.27)$ & $1.18(1.09-1.29)$ & $1.28(1.18-1.39)$ & $1.16(1.07-1.26)$ & .0001 \\
\hline $\begin{array}{l}\text { Model 2: Multivariate } \\
\quad(95 \% \mathrm{Cl})\end{array}$ & 1.00 & $1.10(1.00-1.20)$ & $1.12(1.02-1.22)$ & 1.21 (1.10-1.33) & 1.19 (1.07-1.32) & .0004 \\
\hline \multicolumn{7}{|l|}{ Sucrose } \\
\hline $\begin{array}{l}\text { Model 1: Age-adjusted } \\
(95 \% \mathrm{Cl})\end{array}$ & 1.00 & $1.13(1.04-1.23)$ & $1.20(1.10-1.30)$ & $1.17(1.08-1.27)$ & $1.11(1.02-1.21)$ & .03 \\
\hline $\begin{array}{l}\text { Model 2: Multivariate } \\
\quad(95 \% \mathrm{Cl})\end{array}$ & 1.00 & $1.10(1.01-1.20)$ & $1.20(1.10-1.32)$ & $1.27(1.15-1.39)$ & $1.36(1.22-1.51)$ & $<.0001$ \\
\hline \multicolumn{7}{|l|}{ Fructose } \\
\hline $\begin{array}{l}\text { Model 1: Age-adjusted } \\
\quad(95 \% \mathrm{Cl})\end{array}$ & 1.00 & $1.04(0.96-1.13)$ & 1.03 (0.95-1.12) & $1.04(0.95-1.13)$ & $0.97(0.89-1.05)$ & .18 \\
\hline $\begin{array}{l}\text { Model 2: Multivariate } \\
\quad(95 \% \mathrm{Cl})\end{array}$ & 1.00 & $1.02(0.94-1.11)$ & 1.04 (1.95-1.14) & $1.10(1.00-1.21)$ & $1.10(0.98-1.23)$ & .06 \\
\hline \multicolumn{7}{|l|}{ Lactose } \\
\hline $\begin{array}{l}\text { Model 1: Age-adjusted } \\
\quad(95 \% \mathrm{Cl})\end{array}$ & 1.00 & $1.07(0.98-1.17)$ & $1.13(1.04-1.23)$ & $1.14(1.05-1.24)$ & $1.09(1.00-1.19)$ & $<.08$ \\
\hline $\begin{array}{l}\text { Model 2: Multivariate } \\
\qquad(95 \% \mathrm{Cl})\end{array}$ & 1.00 & $0.98(0.89-1.07)$ & $1.01(0.93-1.10)$ & $1.00(0.91-1.09)$ & $0.95(0.87-1.04)$ & .3 \\
\hline
\end{tabular}

NOTE. Model 1: RR, relative risk adjusting for age (5-year categories); 95\% Cl: 95\% confidence interval.

Model 2: the multivariate model included the same covariates as in model 3 in Table 2. Carbohydrate classified by its chemical structure. All types of carbohydrate included simultaneously. Types of carbohydrate were mutually exclusive; fructose does not include contribution from sucrose.

highest compared with the lowest quintile of dietary glycemic index was 1.33 (95\% CI: $1.21-1.46, P$ for trend <.0001). Addition of types of fats to this model did not appreciably change the positive association between overall dietary glycemic index and risk of cholecystectomy.

Intake of total carbohydrate was significantly associated with risk of cholecystectomy in the multivariate model (Table 2, model 2); the relative risk for the highest compared with the lowest quintile of dietary carbohydrate, representing the effect of replacing fat with carbohydrate, was 1.16 (95\% CI: $1.04-1.30, P$ for trend $=$ $.0001)$. When total carbohydrate was entered into the multivariate nutrient-density model as a continuous variable, the relative risk was 1.06 (95\% CI: $1.03-1.09, P$ for trend $<.0001)$ for an increase of $5 \%$ in energy from total carbohydrate, as compared with the equivalent energy from total fat. With additional adjustment with saturated and trans fats (Table 2, model 3), the relative risk was 1.35 (95\% CI: $1.17-1.55, P$ for trend $<.0001$ ) when extreme quintiles were compared. Carbohydrates have been classified as complex (polysaccharides, mainly starch) or simple (monosaccharides and disaccharides). We therefore examined the relation of these mutually exclusive types of carbohydrate to the risk of cholecystectomy. In the multivariate models, we found that starch, sucrose, and fructose each had a positive relationship with the risk of cholecystectomy, whereas lactose was not associated with the risk (Table 3).

To examine whether the association with carbohydrate intake was modified by risk factors for gallstone disease, we repeated the multivariate analyses within subgroups of potential confounding variables. The positive associations between carbohydrate intake and the risk of cholecystectomy persisted, and there was no important change in effect.

To evaluate the potential for detection bias because of increased medical surveillance, we additionally excluded women without a routine medical checkup between 1986 and 1988. Compared with women in the lowest quintile of carbohydrate intake, women in the highest quintile of carbohydrate had a multivariate relative risk of 1.31 (95\% CI: $1.13-1.53, P$ for trend $<.0001$ ).

Because diabetes mellitus may be a direct consequence of high carbohydrate intake, we deliberately did not control for it. However, to assess any residual effect we added this potential biologic mediator into the multivariate models. After adjustment for diabetes and other risk factors, the significant positive association was little altered, even after controlling for this potential biologic mediator. The multivariate relative risk for women in the highest quintile of carbohydrate compared with women 
in the lowest quintile was 1.35 (95\% CI: $1.17-1.55, P$ for trend <.0001).

\section{Discussion}

In this 16 -year prospective cohort study among women, we found that a higher intake of carbohydrate was positively associated with the risk of cholecystectomy. A significant positive association was also found for dietary glycemic load and glycemic index.

Studies regarding carbohydrate intake and risk of gallstone disease have been inconsistent. In a population study in Italy, a positive association was observed between a high carbohydrate intake and an increased incidence of gallstone. ${ }^{7}$ In 2 larger case-control studies, one in Italy and the other in Australia, an increased risk for sugar intake was seen. ${ }^{24,25}$ In a prospective cohort study in The Netherlands, a 2-fold greater risk of clinically diagnosed gallstones was found for the highest tertile of sugar intake relative to the lowest. ${ }^{26}$ In a cross-sectional study in Copenhagen, higher intake of refined sugar was not associated with increased gallstone prevalence. ${ }^{27}$ In a population-based study in Mexican Americans, high level of sucrose intake was not related to risk of gallstone. ${ }^{28}$ The inconsistency among these studies may arise from imprecise or nonvalidated assessment of nutrients, suboptimal study design, lack of long-term dietary information, limited control for potential confounders, and small sample size.

High intake of carbohydrates can stimulate synthesis of VLDL cholesterol, raise plasma triglycerides, and reduce HDL cholesterol in the liver. ${ }^{89}$ In a prospective, randomized, long-term, outpatient study in free-living subjects lasting up to 2 years, ${ }^{29}$ high carbohydrate intake was associated with an increase in plasma triglyceride level and a reduction in HDL cholesterol level. Also, low plasma HDL cholesterol and high triglyceride levels have been associated with an increased risk of gallstone disease. ${ }^{7,30}$ Carbohydrates also can have an immediate effect on postprandial glucose and insulin responses. A low-fat, high-carbohydrate diet may increase the incidence of glucose intolerance, type 2 diabetes mellitus, hyperinsulinemia, and insulin resistance and, thereby, may facilitate gallstone formation. ${ }^{10,11}$ In metabolic trials, low-fat, high-carbohydrate diets decreased insulin sensitivity in the subjects. ${ }^{31,32}$ These diets further worsened dyslipidemia in subjects who were prone to insulin resistance. ${ }^{33}$ Moreover, diets with high glycemic index and glycemic load diets have been reported to increase postprandial glucose and insulin responses, decrease insulin sensitivity, and derange lipid profiles, ${ }^{34-36}$ which may increase the risk of gallstone disease.
In this study, the possibility of misclassification might be of concern because information on nutrient intake was collected by self-report. Random within-person variation could attenuate any true association of interest, but the semiquantitative food-frequency questionnaire was designed to minimize this error by assessing average longterm dietary intake during the successive follow-up periods. These repeated measurements took into account possible changes in diet with time and reduced random variation in reporting. Although the total effects of carbohydrate intake may not be fully captured by the questionnaire, any measurement errors should be unrelated to the end points because of the prospective design. Thus, any nondifferential misclassification would most likely weaken any true relationship.

The prospective design of our study also avoids the potential for differential recall of intake by cases and noncases because all data on food were collected before the end points occurred. Consistently high follow-up rates reduce the possibility that our results are biased by women lost to follow-up in this cohort. Thus, these potential biases would have been minimal.

We evaluated whether confounding could explain the observed positive associations because women who had a higher intake of carbohydrate tended to have a generally healthy lifestyle (see Table 1). Adjustments for these variables did not attenuate but, rather, strengthened the associations. A clear increased risk persisted in the multivariate analyses, which indicated that the associations were independent of these known risk factors. Residual confounding by unknown risk factors is theoretically possible. However, the stronger associations with additional adjustment of a multitude of known or suspected risk factors in the multivariate models argued against this.

The limitation of our study is that we investigated only gallstone disease resulting in cholecystectomy. Our findings are unlikely due to biased ascertainment of cholecystectomy cases, given the study sample of women and the validity of reports of cholecystectomies. Moreover, any under ascertainment of cases would not bias the observed relative risks. ${ }^{22}$ Because it was not possible to perform diagnostic screening procedures for the presence of gallstones in this large study population, we were not able to estimate the incidence of gallstone formation. Our results may not be generalizable to the entire population with gallstone disease. However, our analyses do focus on the clinically relevant faction of gallstone disease.

Although glycemic carbohydrate has been shown to be associated with an increased risk of type 2 diabetes, coronary heart disease, obesity, and cancer over the past 
decade, ${ }^{37,38}$ the usefulness of dietary glycemic index and glycemic load in relation to chronic diseases is still controversial. ${ }^{39-41}$ In addition, the relation between glycemic load or glycemic index and gallstone disease was rarely examined. Because long-term dietary trials on chronic diseases such as gallstones in a large population are not feasible, if not impossible, prospective cohort studies can provide important information. Our data suggest that not only the quality but also the quantity of carbohydrate intake is important in predicting risk of cholecystectomy in women. If glycemic load were the culprit for the risk, then a greater carbohydrate intake may induce a greater insulin demand in the long term and, hence, may significantly correlate with the disease. More mechanistic and clinical studies are needed to corroborate our observation.

In conclusion, our findings suggest that a higher intake of carbohydrate, dietary glycemic load, and glycemic index may increase risk of cholecystectomy in women. These results add to the concern that low-fat, high-carbohydrate diets may not be optimal as a healthy dietary recommendation.

\section{References}

1. Everhart K, Khare M, Hill M, et al. Prevalence and ethnic differences in gallbladder disease in the United States. Gastroenterology 1999;117:632-639.

2. Beckingham IJ. ABC of diseases of liver, pancreas, and biliary system. Gallstone disease. BMJ 2001;322:91-94.

3. National Center for Health Statistics. National Hospital Discharge Survey. Advance data from vital and health statistics, Hyattsville, MD: 2000.

4. Kang JY, Ellis C, Majeed A, et al. Gallstones-an increasing problem: a study of hospital admissions in England between 1989/1990 and 1999/2000. Aliment Pharmacol Ther 2003;17: 561-569.

5. Diehl AK. Epidemiology and natural history of gallstone disease. Gastroenterol Clin North Am 1991;20:1-19.

6. Dowling RH. Pathogenesis of gallstones. Aliment Pharmacol Ther 2000;14(Suppl 2):39-47.

7. Attili AF, Capocaccia R, Carulli N, et al. Factors associated with gallstone disease in the MICOL experience. Hepatology 1997; 26:809-818.

8. Mensink RP, Zock PL, Kester AD, et al. Effects of dietary fatty acids and carbohydrates on the ratio of serum total to HDL cholesterol and on serum lipids and apolipoproteins: a metaanalysis of 60 controlled trials. Am J Clin Nutr 2003;775:11461155.

9. Mancini M, Mattock M, Rabaya E, et al. Studies of the mechanisms of carbohydrate-induced lipaemia in normal man. Atherosclerosis 1973;17:445-454.

10. Ruhl CE, Everhart JE. Association of diabetes, serum insulin, and C-peptide with gallbladder disease. Hepatology 2000;31:299-303.

11. Dubrac S, Parquet M, Blouquit Y, et al. Insulin injections enhance cholesterol gallstone incidence by changing the biliary cholesterol saturation index and apo A-I concentration in hamsters fed a lithogenic diet. J Hepatol 2001;35:550-557.

12. Jenkins DJ, Wolever TMS, Taylor RH, et al. Glycemic index of foods: a physiological basis for carbohydrate exchange. Am J Clin Nutr 1981;34:362-366.
13. Wolever TMS, Jenkins DJ. The use of the glycemic index in predicting the blood glucose response to mixed meals. Am J Clin Nutr 1986;43:167-172.

14. Frost F, Leeds A, Trew G, et al. Insulin sensitivity in women at risk of coronary heart disease and the effect of a low glycemic diet. Metabolism 1998;47:1245-1251.

15. Colditz GA, Manson DM, Hankinson SE. The Nurses' Health Study: 20-year contribution to the understanding of health among women. J Womens Health 1997;6:49-62.

16. Willett WC. Nutritional epidemiology. 2nd ed. New York: Oxford University Press, 1998.

17. US Department of Agriculture. Composition of foods-raw, processed, and prepared, 1963-1992. Agricultural handbook no. 8 series, Washington, DC: Department of Agriculture, US Government Printing Office, 1993.

18. Wolever TMS, Jekins DJ, Jekins AL, et al. The glycemic index: methodology and clinical implications. Am J Clin Nutr 1991;54: $846-854$

19. Liu S, Manson JE, Stampfer MJ, et al. Dietary glycemic load assessed by food-frequency questionnaire in relation to plasma high-density-lipoprotein cholesterol and fasting plasma triacylglycerols in postmenopausal women. Am J Clin Nutr 2001;73: 560-566.

20. Sleisenger MH, Fordtran JS, eds. Gastrointestinal and liver disease: pathophysiology, diagnosis, management. Philadelphia, PA: Saunders, 2002.

21. Hu FB, Stampfer MJ, Rimm E, et al. Dietary fat and coronary heart disease: a comparison of approaches for adjusting for total energy intake and modeling repeated dietary measurements. Am J Epidemiol 1999;149:531-540.

22. Rothman KJ, Greenland S. Modern epidemiology. Philadelphia, PA: Lippincott Williams \& Wilkins, 1998.

23. Cox DR, Oakes D. Analysis of survival data. London: Chapman \& Hall, 1984.

24. Scragg KR, McMichael AJ, Baghurst PA. Diet, alcohol, and relative weight in gallstone disease: a case-control study. BMJ 1984; 288:1113-1119.

25. Alessandrini A, Busco MA, Gatti E, et al. Dietary fibres and cholesterol gallstones: a case control study. Ital J Gastroentero 1982;14:156-158

26. Moerman CJ, Wmeets FWM, Kromhout D. Dietary risk factors for clinically diagnosed gallstones in middle-aged men. Ann Epidemiol 1994;4:248-254.

27. Jorgensen T, Jorgensen LM. Gallstones and diet in a Danish population. Scand J Gastroenterol 1989;24:821-826.

28. Diehl AK, Haffner SM, Knapp JA, et al. Dietary intake and the prevalence of gallbladder disease in Mexican Americans. Gastro enterology 1989;97:1527-1533.

29. Retzlaff BM, Walden CE, Dowdy AA, et al. Changes in plasma triacylglycerol concentrations among free-living hyperlipidemic men adopting different carbohydrate intakes over two years: the Dietary Alternative Study. Am J Clin Nutr 1995;62:988-995.

30. Fuchs $\mathrm{M}$, Ivandic $\mathrm{B}$, Muller $\mathrm{O}$, et al. Biliary cholesterol hypersecretion in gallstone-susceptible mice is associated with hepatic up-regulation of the high-density lipoprotein receptor SRBI. Hepatology 2001;33:1451-1459.

31. Garg A, Grundy SM, Koffler M. Effect of high carbohydrate intake on hyperglycemia, islet function, and plasma lipoproteins in NIDDM. Diabetes Care 1992;15:1572-1580.

32. Garg A, Bantle JP, Henry RR, et al. Effects of varying carbohydrate content of diet in patients with non-insulin-dependent diabetes mellitus. JAMA 1994;271:1421-1428.

33. Jeppesen J, Chen YD, Zhou MY, et al. Effect of variations in oral fat and carbohydrate load on postprandial lipemia. Am J Clin Nutr 1995;62:1201-1205. 
34. Frost F, Leeds A, Trew G, et al. Insulin sensitivity in women at risk of coronary heart disease and the effect of a low glycemic diet. Metabolism 1998;47:1245-1251.

35. Jenkins DJ, Kendall CW, Augustin LS, et al. High-complex carbohydrate or lente carbohydrate foods? Am J Med 2002;113(Suppl 9B):S30-S37.

36. Morris KL, Zemel MB. Glycemic index, cardiovascular disease, and obesity. Nutr Rev 1999;57:273-276.

37. Brand-Miller JC. Glycemic load and chronic disease. Nutr Rev 2003;61:S49-S55.

38. Colombani PC. Glycemic index and load-dynamic dietary guidelines in the context of diseases. Physiol Behav 2004;83:603-610.

39. Pi-Sunyer FX. Glycemic index and disease. Am J Clin Nutr 2002; 76:S290-S298.

40. Augustin LS, Franceschi S, Jenkins DJ, et al. Glycemic index in chronic disease: a review. Eur J Clin Nutr 2002;56:1049-1071.
41. Franz MJ. The glycemic index: not the most effective nutrition therapy intervention. Diabetes Care 2003;26:2466-2468.

Received January 19, 2005. Accepted March 16, 2005.

Address correspondence to: Chung-Jyi Tsai, MD, ScD, Division of Digestive Diseases and Nutrition, University of Kentucky Medical Center, 800 Rose Street, Lexington, Kentucky 40536-0298. e-mail: hpcjt@channing.harvard.edu; fax: (859) 257-8860.

Supported by research grants (CA55075 and DK46200) from the National Institutes of Health.

The authors thank the participants in the Nurses' Health Study for their continuing dedication and commitment to the study and the research staff in the Nurses' Health Study for their expert assistance. 